\title{
Hippocampal CysLT1R overexpression or activation accelerates memory deficits, synaptic dysfunction, and amyloidogenesis in young APP/PS1 transgenic mice
}

\author{
Shun-Chang Fang, Jun-Jie Wang, Fang Chen, Su-Su Tang, Rong-Hao Mu, Dan-Hua Yuan, Jia-Jia Zhao, \\ Hao Hong, Yan Long \\ Department of Pharmacology, Key Laboratory of Neuropsychiatric Diseases, China Pharmaceutical University, Nanjing, China \\ Contributions: (I) Conception and design: H Hong, Y Long; (II) Administrative support: SC Fang; (III) Provision of study materials or patients: JJ \\ Wang, F Chen, SS Tang; (IV) Collection and assembly of data: RH Mu, DH Yuan; (V) Data analysis and interpretation: JJ Zhao, SC Fang; (VI) \\ Manuscript writing: All authors; (VII) Final approval of manuscript: All authors. \\ Correspondence to: Yan Long. Department of Pharmacology, China Pharmaceutical University, 24 Tongjia Alley., Nanjing 210009 , China. \\ Email: long7027610@163.com.
}

Background: Our previous studies demonstrated that cysteinyl leukotrienes receptor 1 (CysLT $\left.{ }_{1} \mathrm{R}\right)$ knockout, pharmacological blockade, or hippocampus knockdown produced beneficial effects against Alzheimer's disease (AD); however, whether $\mathrm{Cys}_{1} \mathrm{R}$ upregulation has deleterious effects on $\mathrm{AD}$ remains elusive.

Methods: In this study, we investigated the changes in behaviors, hippocampal amyloidogenesis, and synapse plasticity after $\mathrm{CysLT}_{1} \mathrm{R}$ overexpression by microinfusion of the lentiviral vector, containing its coding sequence of mouse ( $\left.\mathrm{LV}-\mathrm{CysLT}_{1} \mathrm{R}\right)$, into the bilateral dentate gyri (DG) of the hippocampus or CysLT $_{1} \mathrm{R}$ activation by repeated systemic administration of its agonist YM-17690 (0.1 mg/kg, once a day, i.p., for $28 \mathrm{~d})$.

Results: The behavior data showed that overexpression of $\mathrm{Cys}_{1} \mathrm{LT}_{1} \mathrm{R}$ in hippocampal DG or administration of YM-17690 deteriorated behavioral performance in Morris water maze (MWM), Y-maze tests, and novel object recognition (NOR) in young APP/PS1 mice. The further studies showed that these treatments significantly destroyed synaptic function, as evidenced by impaired hippocampal long-term potentiation (LTP), decreased spine density, low number of synapses, and decreased postsynaptic protein (PSD95), and promoted the generation of amyloid $\beta(A \beta)$ through increased expression of BACE1 and PS1 in the hippocampus of young APP/PS1 mice.

Conclusions: Together, our results indicate that $\mathrm{CysLT}_{1} \mathrm{R}$ upregulation accelerates memory impairment in young APP/PS1 mice, which is associated with promoting synaptic dysfunction and amyloidogenesis in the hippocampus.

Keywords: Cysteinyl leukotrienes receptor $1\left(\operatorname{CysLT}_{1} \mathrm{R}\right)$; Alzheimer's disease (AD); memory; synaptic plasticity; amyloidogenesis

Submitted Aug 05, 2021. Accepted for publication Oct 02, 2021.

doi: $10.21037 / \mathrm{atm}-21-4518$

View this article at: https://dx.doi.org/10.21037/atm-21-4518

\section{Introduction}

Alzheimer's disease (AD) is a progressive synaptic failure disease related to age, characterized by progressive cognitive and behavioral impairments such as the inability to make new memories and loss of important past memories (1). Although the pathogenesis and mechanism of $\mathrm{AD}$ progression remain unclear, amyloid $\beta(\mathrm{A} \beta)$ plaques and neurofibrillary tangles are the two principal 
neuropathological hallmarks of $\operatorname{AD}(2,3)$. Therapies targeting $A \beta$ have failed to show clinical efficacy, but the evidence of $A \beta$ aggregates in post-mortem analysis (autopsy), in neuroimaging diagnosis, and data from genetic and biochemical studies lead researchers to think that they cannot rule out the role of $\mathrm{A} \beta$ in $\mathrm{AD}(4,5)$. According to the amyloid cascade hypothesis, the accumulation of $\mathrm{A} \beta$ peptide and consequent aggregation and deposition in the form of amyloid plaques is the main cause of the neurodegenerative process of $\mathrm{AD}$ (6). Current treatment for $\mathrm{AD}$ (donepezil, galantamine, rivastigmine, and memantine) is only symptomatic and has modest benefits. Thus, the development of drugs with the potential to influence disease progression has become a priority (7).

Cysteinyl leukotriene receptor $1\left(\mathrm{CysLT}_{1} \mathrm{R}\right)$ is an important $G$ protein-coupled receptor mediating the biological functions of cysteinyl leukotrienes and mostly expressed in lung smooth muscle cells, interstitial lung macrophages, and the spleen, and it has been thoroughly studied elucidating its role in the etiology of airway inflammation and asthma (8). Antagonists of $\mathrm{CysLT}_{1} \mathrm{R}$, such as montelukast, zafirlukast, and pranlukast, have been established as important therapeutics for clinical management of asthma for more than a decade (9). Recently, some studies on CysLT ${ }_{1} \mathrm{R}$ have focused on its novel pathophysiological role in CNS disorders, such as cerebral ischemia (10), traumatic brain injury $(11,12)$, experimental autoimmune encephalomyelitis (13), and more. We reported that intracerebral infusions of LTD4, a cysteinyl leukotriene, led to memory impairment in normal mice (14), and $\mathrm{CysLT}_{1} \mathrm{R}$ antagonists montelukas or pranlukast produced significant protection against cognitive impairment induced by $A \beta$, lipopolysaccharide, and streptozotocin in mice (15-19). Recently, we generated APP/PS1-CysLT $\mathrm{R}^{-/-}$mice, and performed lentivirus-mediated knockdown of $\mathrm{CysLT}_{1} \mathrm{R}$ gene in the hippocampus of APP/PS1 mice, which revealed that CysLT $_{1} \mathrm{R}$ knockout or knockdown could conserve synaptic structure and plasticity, and improve cognition in APP/ PS1 mice (20). But it is little known that whether CysLT ${ }_{1} \mathrm{R}$ upregulation accelerate AD progression. To further clarify the role of $\mathrm{CysLT}_{1} \mathrm{R}$ in $\mathrm{AD}$, we herein investigated effects of hippocampal Cys $\mathrm{LT}_{1} \mathrm{R}$ overexpression or pharmacological activation on memory deficits, synaptic dysfunction, and amyloidogenesis in young APP/PS1 transgenic mice. We present the following article in accordance with the ARRIVE reporting checklist (available at https://dx.doi.org/10.21037/atm-21-4518).

\section{Methods}

\section{Materials}

The following antibodies were purchased: rabbit antiCysLT $_{1} \mathrm{R}$ from Cayman Chemical (Ann Arbor, MI, USA); rabbit anti-APP, rabbit anti-BACE, rabbit anti-PSD-95, and rabbit anti-PS1 from Cell Signaling Technology, Inc. (Danvers, MA, USA); rabbit anti- $\beta$-actin from Boster Biotechnology Co., Ltd. (Pleasanton, CA, USA); Alexa Fluor 488 donkey anti-rabbit IgG were purchased from SigmaAldrich Co. LLC (St. Louis, MO, USA). All other chemicals were of analytical grade and commercially available.

\section{Animals}

Male APP/PS1 $\triangle \mathrm{E} 9$ mice (herein referred to as APP/PS1) and their wild-type (WT) littermates were constructed and bred by Model Animal Research Center of Nanjing University (Nanjing, China). The experimental procedures involving animals and their care were conducted in compliance with the ARRIVE (Animal Research: Reporting of in Vivo Experiments) guidelines (21,22). Experiments were performed under a project license granted by China Pharmaceutical University, in compliance with guidelines of China Pharmaceutical University for the care and use of animals.

\section{Stereotaxic injection of lentivirus in mouse brain}

At 5 months of age, WT and APP/PS1 mice were anaesthetized with chloral hydrate $(350 \mathrm{mg} / \mathrm{kg})$. Bilateral hippocampal dentate gyri (DG) injection of $\mathrm{LV}-\mathrm{CysLT}_{1} \mathrm{R}$ EGFP (GeneChem Co., Ltd., Shanghai, China) was performed stereotactically at coordinates $2.1 \mathrm{~mm}$ to posterior, $1.7 \mathrm{~mm}$ to lateral, and $2.1 \mathrm{~mm}$ to ventral relative to brain bregma of APP/PS1 mice. Lentiviral vectorfunctional enhanced green fluorescent protein (LVEGFP) served as the control vector. A volume of $2.5 \mu \mathrm{L}$ of viral suspension containing $2.5 \times 10^{6}$ vector genome (virus titration) was injected at a rate of $0.25 \mu \mathrm{L} / \mathrm{min}$. After 4 weeks, the mice underwent behavioral testing and biochemical examinations.

\section{Western blot}

Hippocampus was homogenized in radioimmunoprecipitation assay (RIPA) buffer [50 mM Tris- $\mathrm{HCl}(\mathrm{pH} 7.4), 150 \mathrm{mM}$ $\mathrm{NaCl}, 1 \mathrm{mM}$ phenylmethylsulfonyl fluoride (PMSF), $1 \mathrm{mM}$ ethylenediamine tetraacetic acid (EDTA), 1\% Triton 
X-100, $1 \%$ sodium deoxycholate, $0.1 \%$ sodium dodecyl sulfate (SDS)] and centrifuged at $12,000 \mathrm{~g}$ for $15 \mathrm{~min}$. Protein concentrations were determined by bicinchoninic acid (BCA) assay kit (Beyotime, Jiangsu, China). Proteins samples were separated on $12 \%$ SDS-polyacrylamide gels and transferred onto polyvinylidene fluoride membranes. The membranes were blocked for $2 \mathrm{~h}$ with $5 \%$ fat-free milk and incubated overnight at $4{ }^{\circ} \mathrm{C}$ with primary rabbitderived antibodies. After washing with Tris-buffered saline containing $0.1 \%$ Tween 20 (TBST) 3 times, the membranes were incubated with an appropriate secondary antibody $(1: 5,000)$ for $2 \mathrm{~h}$ at room temperature. The antibodyreactive bands were visualized using Tanon gel imaging system (23).

\section{Immunofluorescence}

Mice were transcardially perfused with $4 \%$ paraformaldehyde, their brains were then post-fixed overnight in $4 \%$ paraformaldehyde at $4{ }^{\circ} \mathrm{C}$, and dehydrated in $30 \%$ sucrose until isotonic. Afterwards, $25 \mu \mathrm{m}$ coronal sections were sliced on a freezing microtome (Leica, Wetzlar, Germany). After blocking in $2 \%$ serum for $2 \mathrm{~h}$, sections were incubated in primary antibody overnight. On the second day, the sections were incubated with secondary antibody and then washed in phosphate-buffered saline (PBS, $3 \times 5 \mathrm{~min}$ ). The sections examined using fluorescence microscopy (Leica) (24).

\section{Enzyme-linked immunosorbent assay}

Detection of $\mathrm{A} \beta$ was performed as described previously (20). All procedures were performed in accordance with the manufacturer's instructions. Briefly, fractions of the hippocampi (100-120 mg) were homogenized in ice-cold lysis buffer containing proteinase inhibitor cocktail. After $15 \mathrm{~min}$ of incubation on ice, homogenates were centrifuged at $14,000 \mathrm{~g}$ for $15 \mathrm{~min}$ at $4{ }^{\circ} \mathrm{C}$, leaving the supernatant containing triton-soluble $\mathrm{A} \beta$ peptides. The triton-insoluble pellets were then extracted using $5 \mathrm{M}$ guanidine- $\mathrm{HCl}$, and were briefly re-homogenized and shaken for $4 \mathrm{~h}$ at room temperature to promote extraction of insoluble $A \beta$. The homogenates were centrifuged for $5 \mathrm{~min}$ at $8,000 \mathrm{~g}$. Tritonsoluble and guanidine-HCl-soluble fractions were used as input for enzyme-linked immunosorbent assay (ELISA) detection of $\mathrm{A} \beta_{1-40}$ or $\mathrm{A} \beta_{1-42}$. Total protein concentrations were determined in each fraction by BCA protein assay. Levels of proteins were measured using ELISA kits $\left(\mathrm{A} \beta_{1-40}\right.$ or $\mathrm{A} \beta_{1-42}$ ELISA kit, Cusabio Biotech Co. Ltd.,
Wuhan, China).

\section{Hippocampal slice preparation and electrophysiology}

Hippocampal transversal slices from 6-month-old WT and APP/PS1 mice were prepared using a vibratome as described previously. Briefly, mice hippocampal slices were placed in a recording chamber and perfused with artificial cerebrospinal fluid (ACSF) at $24^{\circ} \mathrm{C}$. Schaffer collaterals were stimulated with a tungsten monopolar electrode. The field excitatory postsynaptic potentials (fEPSPs) were recorded from the CA1 stratum radiatum by a glass microelectrode filled with ACSF with resistance of 3-4 M $\Omega$. Then, fEPSPs were recorded under current-clamp mode. Long term potentiation (LTP) was induced with a highfrequency stimulation protocol consisting of two onesecond long $100 \mathrm{~Hz}$ trains (16).

\section{Golgi staining}

Mouse brains were removed and Golgi staining was performed using an FD Rapid Golgi Stain Kit (FD Neuro Technologies, Ellicot City, MD, USA) as described. The brains were immersed in solution A and B for 2 weeks and then in solution $\mathrm{C}$ for $48 \mathrm{~h}$. Brain samples were serially sectioned into $100 \mu \mathrm{m}$ coronal slices with a freezing microtome. Slides were then stained with solution D: solution $\mathrm{E}$ mixture solutions for $5 \mathrm{~min}$. The sections were dehydrated with graded alcohol solutions, cleared in xylene, and cover slipped. The preparations were observed under a microscope. For morphological analysis of hippocampal DG neurons, 5 granule neurons from each mouse (4 mice/group, 20 neurons from each group) were calculated from the hippocampal DG. The number of spines was quantified by ImageJ (https://imagej.nih.gov/ij/). Spine density was calculated per $10 \mu \mathrm{m}$ of dendritic length (25).

\section{Electron microscopy}

After deep anesthesia, mice were perfused transcardially with $2 \%$ glutaraldehyde and $3 \%$ paraformaldehyde in PBS. Hippocampal slices were then prepared and fixed in cold $1 \%$ OsO4 for $1 \mathrm{~h}$. Ultrathin sections $(90 \mathrm{~nm})$ were stained with uranyl acetate and lead acetate, and viewed at $100 \mathrm{kV}$ in a JEOL 200CX electron microscope (JEOL USA Inc., Peabody, MA, USA). Synapses were identified by the presence of synaptic vesicles and postsynaptic densities. The number of synapses was independently counted by two 
Page 4 of 11

investigators, who were blind to age and species (26).

\section{Morris water maze (MWM)}

The mice were assessed for spatial learning and memory in the MWM. During day 1-2 of visible platform training, the platform location was indicated by a flag. During day 3-5, we removed the flag and let the mice discover the hidden platform. Each animal was trained at each quadrant with $1 \mathrm{~h}$ interval between trials. The animal had to find the platform in $90 \mathrm{~s}$. If it could not reach the platform within $90 \mathrm{~s}$, the animal was placed on the platform by an experimenter for $30 \mathrm{~s}$. At day 6, mice freely explored in the pool for $90 \mathrm{~s}$ without the hidden platform (27).

\section{Y-maze avoidance tests}

The maze was constructed with $10 \mathrm{~cm}$ high walls and a stainless floor. The mice were tested for 2 days. On training day, the mouse firstly moved freely for $5 \mathrm{~min}$. Then during the learning trial, electric shocks $(2 \mathrm{~Hz}, 125 \mathrm{~ms}, 10 \mathrm{~V})$ were given in two sectors of the maze through the stainless floor and the light was on in the non-electric sector. Each mouse was trained 10 times. After remaining in the nonelectric sector for $30 \mathrm{~s}$, the training was stopped, and this was recorded as a correct choice. The experimenter was required to let the mouse stay in the non-electric sector for $30 \mathrm{~s}$ when the mouse failed at entering the sector. On testing day, the same procedure was repeated 10 times (17).

\section{Novel object recognition (NOR) test}

On the first day, mice were familiarized with the chamber for $10 \mathrm{~min}$. After $24 \mathrm{~h}$, mice were allowed to explore the same two objects for $5 \mathrm{~min}$. The next day, mice were exposed to two different objects, one familiar object and one novel object, for $5 \mathrm{~min}$ each object. The discrimination index was used to reflect the exploration time of the novel object, expressed as the ratio of the total time spent exploring both novel and familiar objects (27).

\section{Statistical analysis}

Group differences in the MWM escape latencies were analyzed using a repeated measure analysis of variance (ANOVA) with "days" as the within-subject factor and "group" as the between-subject factor. The remaining data were analyzed using either Student's $t$-test (2-group
Fang et al. CysLT1R accelerates memory deficits in APP/PS1 mice

comparison) or one-way ANOVA (for more than two groups) followed by a Dunnett's post-hoc analysis, if deemed necessary. Descriptive data were presented as means \pm standard error of the mean (SEM). All analyses were carried out using SPSS 20.0 (IBM Corp., Armonk, NY, USA). A P value $<0.05$ was considered statistically significant.

\section{Results}

\section{Hippocampal CysLT $R$ R overexpression or activation accelerates cognitive impairment in young APP/PS1 transgenic mice}

Our previous studies showed that hippocampal CysLT ${ }_{1} \mathrm{R}$ expression increased in APP/PS1 mice with age (20). To confirm the effect of $\mathrm{CysLT}_{1} \mathrm{R}$ upregulation on $\mathrm{AD}$, we delivered lentiviral vector encoding CysLT $_{1} \mathrm{R}$ into the hippocampal DG of young APP/PS1 mice (Figure $1 A$ ). Western blot data showed that hippocampal CysLT $_{1} \mathrm{R}$ expression significantly increased at 3 weeks after the lentivirus injection $\left(\mathrm{F}_{[2,9]}=18.37, \mathrm{P}<0.01\right.$, Figure $\left.1 B, 1 C\right)$. The $M W M$ data showed that the mice in each group exhibited similar escape latency in the visible-platform test $\left(\mathrm{F}_{[2,237]}\right.$ $=9.672, \mathrm{P}>0.05$, Figure $1 D)$, suggesting no influence of the lentiviral vector infusion on vision or basal motivation of mice, and hippocampal $\mathrm{CysLT}_{1} \mathrm{R}$ overexpression significantly increased escape latency in the spatial hiddenplatform variant $\left(\mathrm{F}_{[2,237]}=0.5105, \mathrm{P}<0.05\right.$, Figure $\left.1 E\right)$, decreased time spent in the target quadrant and the number of platform location crossings on day $6\left(\mathrm{~F}_{[2,27]}=11.410\right.$, $\mathrm{P}<0.05$, Figure $1 F ; \mathrm{F}_{[2,27]}=5.884, \mathrm{P}<0.05$, Figure $\left.1 G\right)$ in young APP/PS1 mice. The young APP/PS1 mice with hippocampal $\mathrm{CysLT}_{1} \mathrm{R}$ overexpression exhibited a reduced number of correct choices $\left(\mathrm{F}_{[2,27]}=7.109, \mathrm{P}<0.05\right.$, Figure $\left.1 H\right)$ and more latency to enter the shock-free compartment $\left(\mathrm{F}_{[2,27]}=11.580, \mathrm{P}<0.05\right.$, Figure 11$)$ in the $\mathrm{Y}$ maze test, and showed lower discrimination index $\left(\mathrm{F}_{[2,27]}=16.700, \mathrm{P}<0.05\right.$, Figure 17) in the NOR test. To further confirm detrimental effects of CysLT ${ }_{1} R$, we investigated effects of YM-17690, a specific $\mathrm{Cys}_{1} \mathrm{LT}_{1} \mathrm{R}$ agonist, on behavior performance in young APP/PS1 mice. The results showed that YM-17690 treatment $(0.1 \mathrm{mg} / \mathrm{kg}$, once a day, i.p., for $28 \mathrm{~d})$ produced similar effects on behavior performance in the MWM task (Figure $1 \mathrm{~K}, 1 \mathrm{~L}$ ), Y-maze, and NOR tests (data not shown) with hippocampal $\mathrm{CysLT}_{1} \mathrm{R}$ overexpression in the young APP/PS1 mice. We also used liquid chromatography-mass spectrometry/mass spectrometry (LC-MS/MS) analysis to confirm its presence in the brain after administration 


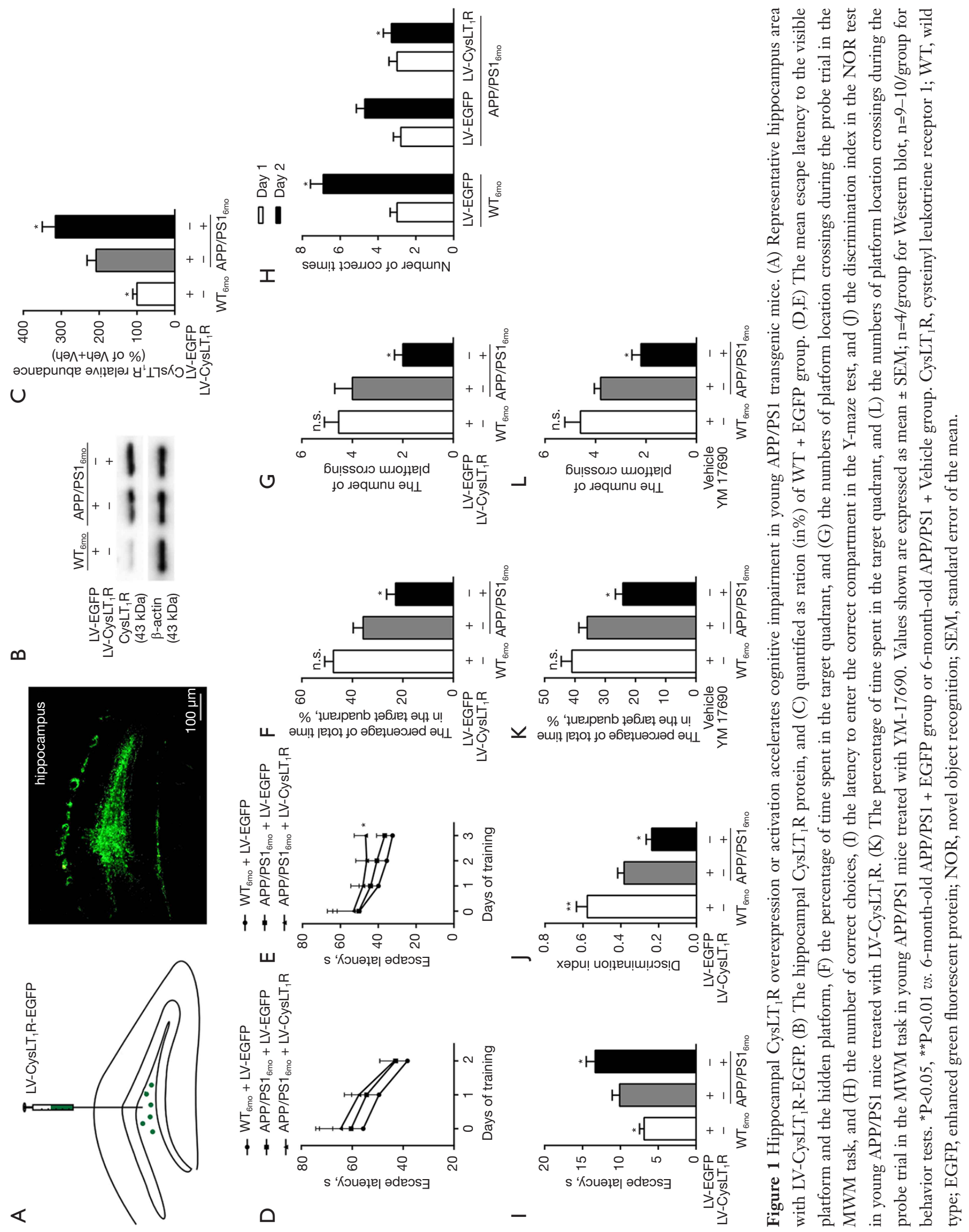


of YM-17690. Assays using LC-MS/MS for YM-17690 content showed that its content in the hippocampus reached the maximum at $0.5 \mathrm{~h}$ after administration, and lasted for $8 \mathrm{~h}$ (data not shown), indicating that it can pass through the blood-brain barrier (BBB).

\section{Hippocampal CysLT $T_{1} R$ overexpression or activation worsened synaptic plasticity deficiency in young APP/PS1 transgenic mice}

Synaptic dysfunction may cause cognitive damage and neurodegeneration $(28,29)$. The present data showed that 6-month-old APP/PS1 mice already had compromised synaptic plasticity, reflected by lower level of fEPSP in the hippocampus, compared to WT mice. When we overexpressed or implemented YM-17690 treatment in young APP/PS1 mice, the level of fEPSP decreased even more significantly $\left(\mathrm{LV}-\mathrm{Cys}_{\mathrm{LT}} \mathrm{R}_{1}: \mathrm{F}_{[2,9]}=7.720\right.$, $\mathrm{P}<0.05$, Figure $2 A, 2 B$; $\mathrm{YM}-17690: \mathrm{F}_{[2,9]}=8.674, \mathrm{P}<0.05$, Figure $2 C, 2 D$ ), suggesting that $\mathrm{CysLT}_{1} \mathrm{R}$ also has a role in disrupting LTP in the early pathogenesis of $\mathrm{AD}$. The number of synapses and dendritic spine densities were also evaluated by the presence of synaptic vesicles observed using an electron microscope and Golgi staining, respectively. The overexpression or activation of $\mathrm{CysLT}_{1} \mathrm{R}$ significantly increased synaptic losses $\left(\mathrm{LV}-\mathrm{CysLT}_{1} \mathrm{R}: \mathrm{F}_{[2,9]}=53.760\right.$, $\mathrm{P}<0.001$, Figure 2E, 2F; YM-17690: $\mathrm{F}_{[2,9]}=37.20, \mathrm{P}<0.001$, Figure $2 E, 2 G$ ), and led to significant decreases in spine density (LV-CysLT ${ }_{1} \mathrm{R}: \mathrm{F}_{[2,9]}=68.270, \mathrm{P}<0.001$, Figure $2 \mathrm{H}, 2 \mathrm{I}$; YM-17690: $\mathrm{F}_{[2,9]}=45.39, \mathrm{P}<0.001$, Figure $27,2 \mathrm{~K}$ ), in younger APP/PS1 mice. The hippocampal PSD-95, a postsynaptic marker, was remarkably decreased (LV-CysLT ${ }_{1} \mathrm{R}$ : PSD95: $\mathrm{F}_{[2,9]}=55.950, \mathrm{P}<0.001$, Figure $2 L, 2 M ; \mathrm{YM}-17690$ : $\mathrm{F}_{[2,9]}=45.51, \mathrm{P}<0.001$, Figure $\left.2 \mathrm{~N}, 2 \mathrm{O}\right)$ in young APP/PS1 transgenic mice with $\mathrm{CysLT}_{1} \mathrm{R}$ overexpression or activation.

\section{Hippocampal CysLT $T_{1}$ overexpression or activation promoted Aß generation in young APP/PS1 transgenic mice}

To determine whether hippocampal CysLT ${ }_{1} R$ overexpression or activation increases amyloidogenesis, we measured A $\beta$, amyloid precursor protein (APP), $\beta$-secretase (BACE1), and PS-1, catalytic subunit of the $\gamma$-secretase enzyme complex, in hippocampi of young APP/PS1 transgenic mice. The results showed that overexpression or activation of $\mathrm{CysLT}_{1} \mathrm{R}$ significantly increased hippocampal $\mathrm{A} \beta_{1-40}$, a TBS-soluble $\mathrm{A} \beta$ (LV-CysLT ${ }_{1} \mathrm{R}: \mathrm{F}_{[1,10]}=7.234$, $\mathrm{P}<0.05 ; \mathrm{YM}-17690: \mathrm{F}_{[1,10]}=5.227, \mathrm{P}<0.05$, Figure $\left.3 A, 3 B\right)$, but still showed immeasurable hippocampal $\mathrm{A} \beta_{1-42}$ in young APP/PS1 transgenic mice. Overexpression or activation of CysLT $_{1} \mathrm{R}$ had no effect on hippocampal APP expression (Figure 3C-3F; LV-CysLT ${ }_{1} \mathrm{R}: \mathrm{F}_{[2,9]}=12.540, \mathrm{P}>0.05$; YM17690: $\left.\mathrm{F}_{[2,9]}=11.73, \mathrm{P}>0.05\right)$ but significantly increased hippocampal BACE1 and PS-1 (Figure 3C,3D,3G-37; LVCysLT ${ }_{1} R$ : BACE: $\mathrm{F}_{[2,9]}=15.740, \mathrm{P}<0.05$; PS-1: $\mathrm{F}_{[2,9]}=16.450$, $\mathrm{P}<0.05$; YM-17690: BACE: $\mathrm{F}_{[2,9]}=21.710, \mathrm{P}<0.05$; PS$\left.1: F_{[2,9]}=16.35, P<0.05\right)$ in young APP/PS1 mice, which suggests that $\mathrm{CysLT}_{1} \mathrm{R}$ upregulation might increase generation of $A \beta$ via promoting the expression of BACE1 and PS-1.

\section{Discussion}

The present studies firstly demonstrated that hippocampal $\mathrm{CysLT}_{1} \mathrm{R}$ overexpression by microinfusion of the lentiviral vector containing its coding sequence into the bilateral DG or activation by repeated systemic administration of its specific agonist YM-17690 accelerated impairments of longterm learning and memory in the MWM task and shortterm memory in the Y-Maze and NOR in young APP/PS1 mice. Simultaneously, these treatments accelerated deficits of synaptic plasticity indicated by decreased synapses and LTP, as well as amyloidogenesis resulting from increased expression of BACE1 and PS-1.

Cognitive function and pathological characteristics are different during different stages of $\mathrm{AD}$ (30). In 6-monthold APP/PS1 mice, the short-term learning and memory is impaired, but the long-term cognitive function is not impacted yet. However, 10-month-old APP/PS1 mice display both short-term and long-term cognitive dysfunction (31-33). The 6-month-old (young) APP/PS1 mice in the present study exhibited obvious impairments of short-term rather than long-term learning and memory. Cysteinyl leukotrienes (including LTC4, LTD4 and LTE4), 5-lipoxygenase (5-LO) metabolites of arachidonic acid, are potent inflammatory mediators, which could bind to CysLT1R to mediate proinflammatory actions. It has been shown that high levels of neuroinflammation could impair the synaptic structure and function, which induce $\mathrm{AD}$ aggravation. Hippocampal $\mathrm{CysLT}_{1} \mathrm{R}$ overexpression and activation not only caused impairment of long-term learning and memory, but also aggravated short-term learning and memory, which indicates that $\mathrm{CysLT}_{1} \mathrm{R}$ participates in progressive decline in cognitive function of $\mathrm{AD}$.

Functional synapse formation is critical for the synaptic transmission in the brain, and synaptic plasticity is the 


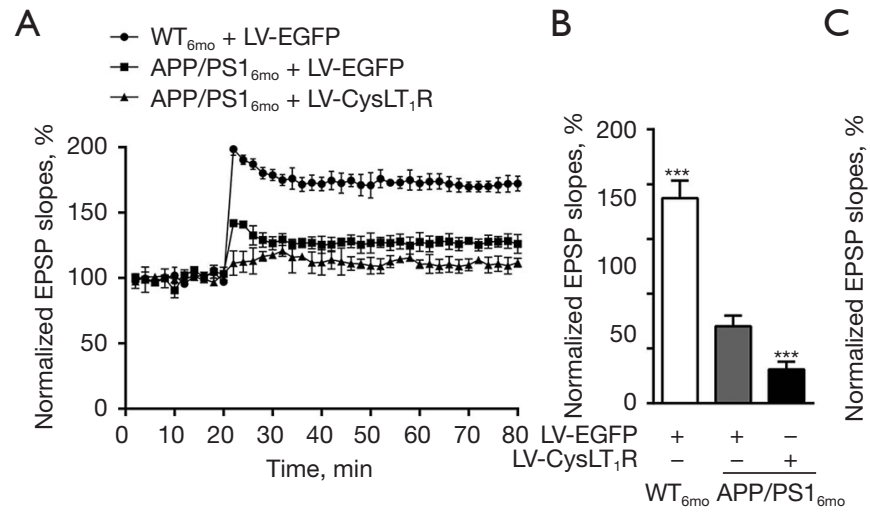

C

$\bullet \mathrm{WT}_{6 \mathrm{mo}}+$ Vehicle

- APP/PS1 $1_{6 \mathrm{mo}}+$ Vehicle

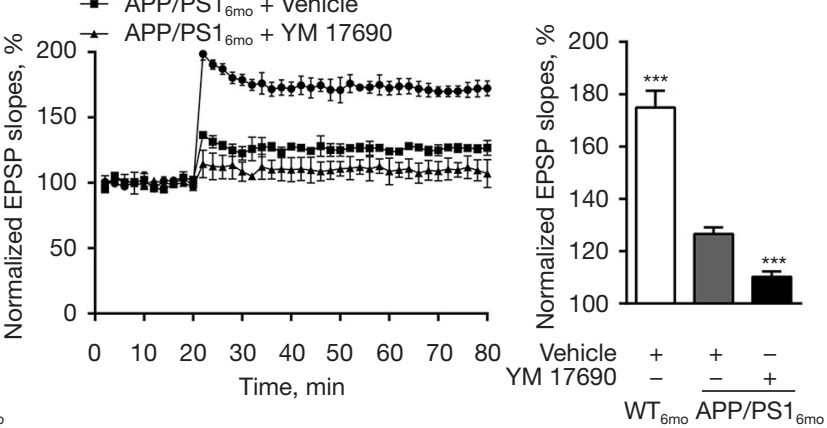

$E$
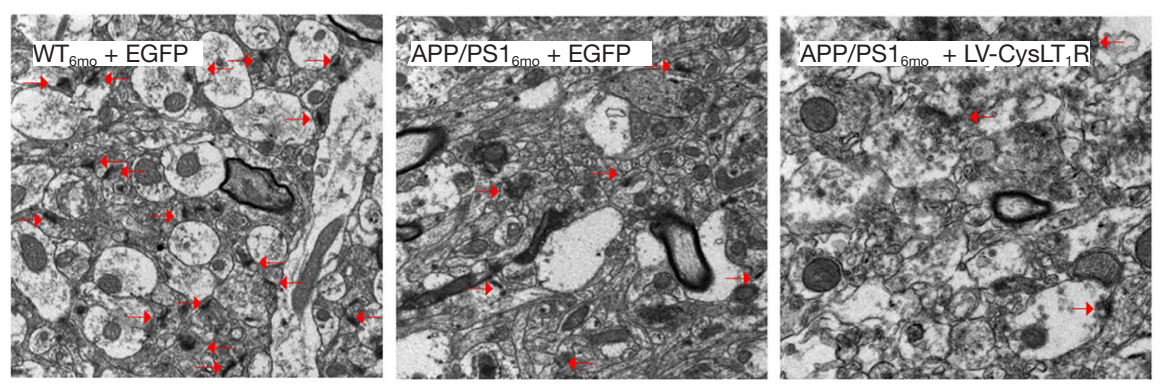

F
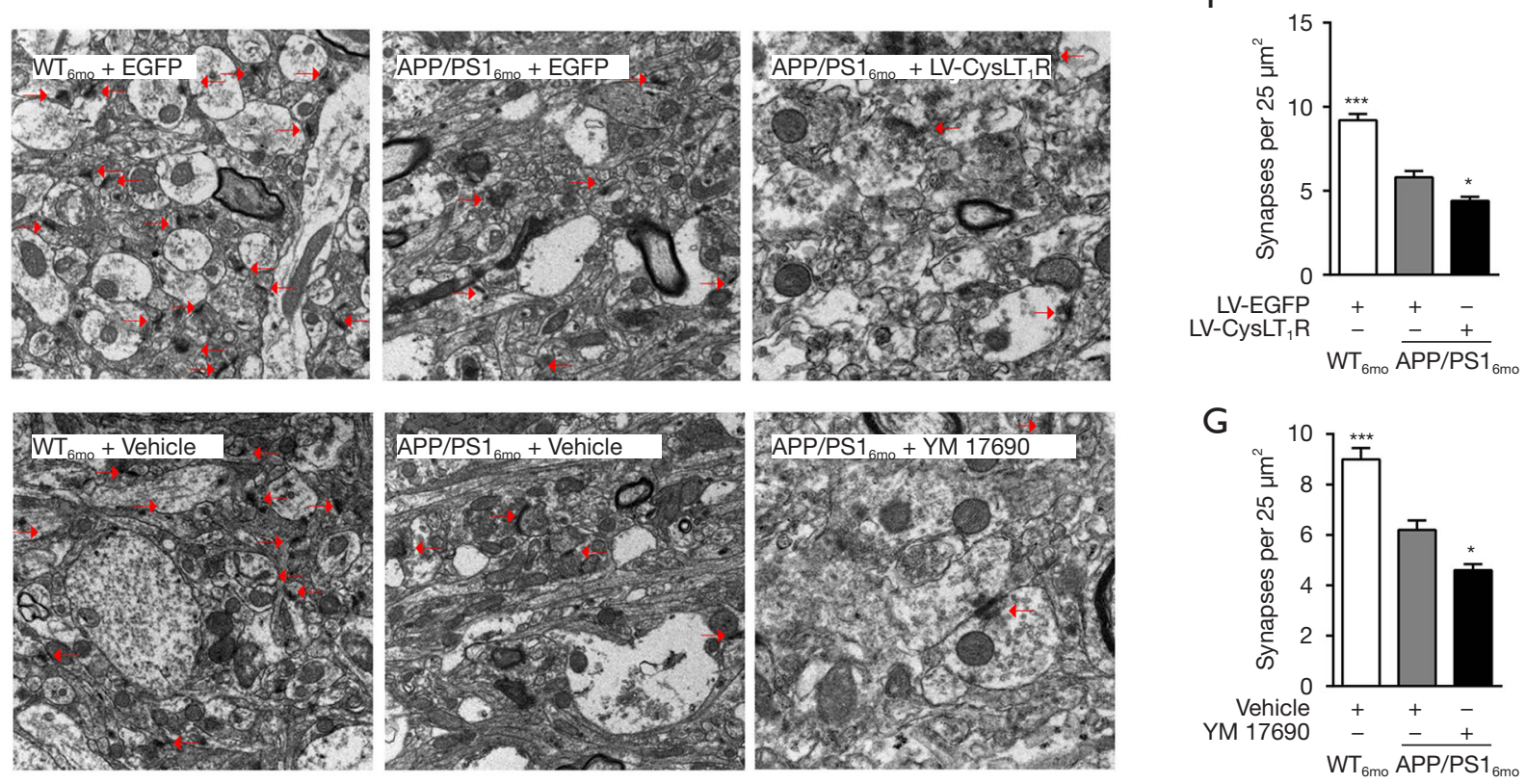

$\mathrm{H}$

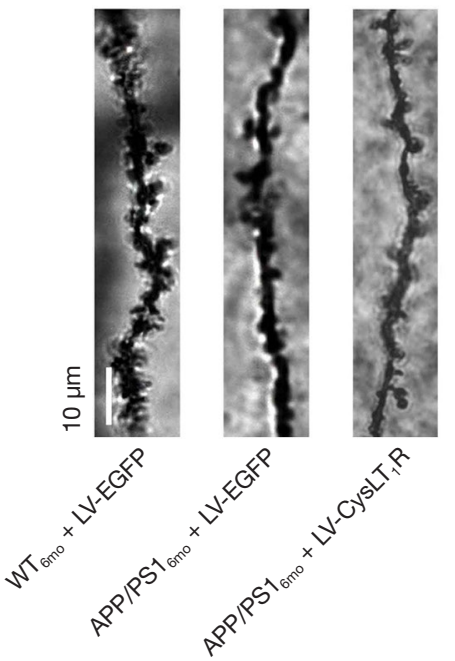

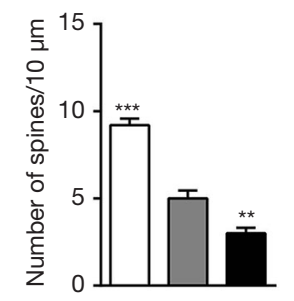

$\begin{array}{rll}\text { LV-EGFP } & + & + \\ \text { V-CysLT } R+ & - & -\end{array}$

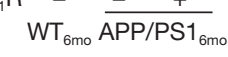

J

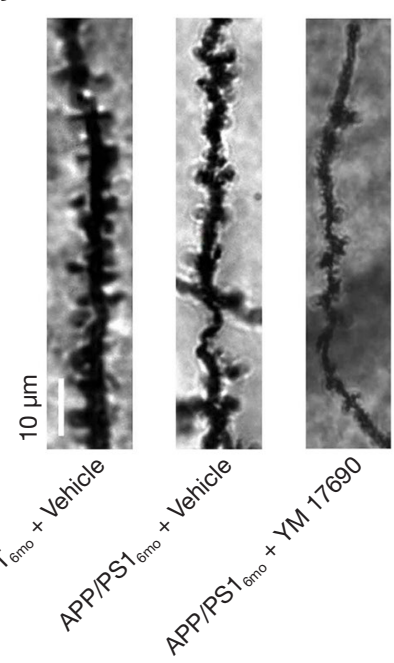

$\mathrm{K}$

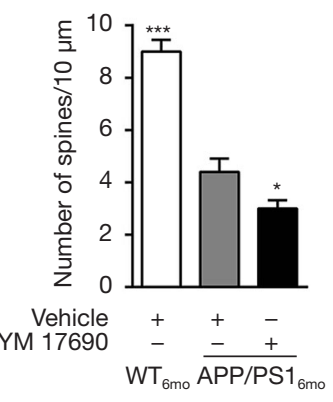


$\mathrm{L}$

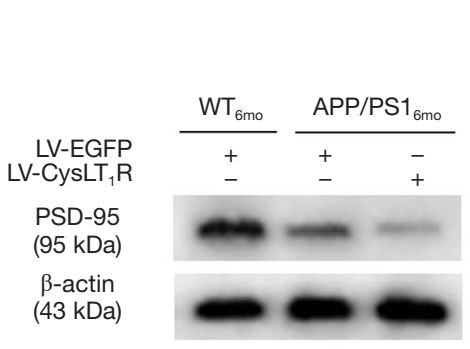

M

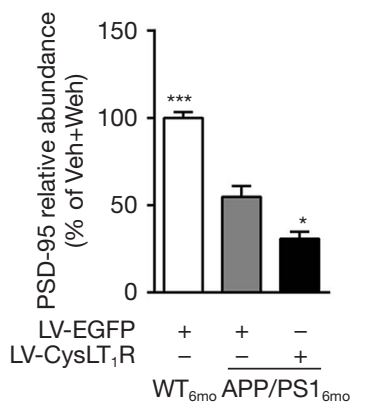

$\mathrm{N}$

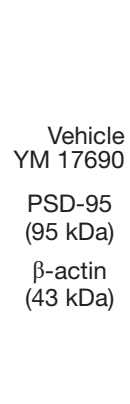

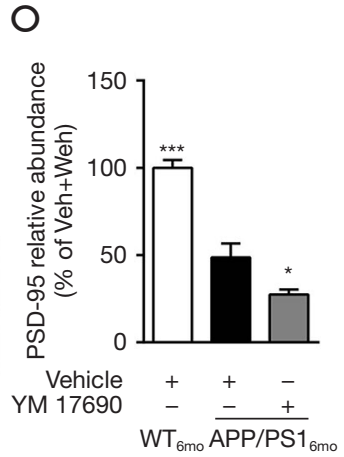

Figure 2 Hippocampal CysLT $T_{1} \mathrm{R}$ overexpression or activation aggravates damages to synaptic structure and function in APP/PS1 transgenic mice. $(\mathrm{A}, \mathrm{C})$ The induction of hippocampal LTP was assessed after high-frequency stimulation and recorded for 60 min post-induction, and (B,D) mean values of fEPSPs were calculated during 55-60 min following the induction of LTP. (E) The synaptic density in the hippocampus was determined by electron microscopy. The red arrows indicate postsynaptic density. Scale bar $=1 \mu \mathrm{m}$. (F,G) statistical analysis of synaptic density calculated as the number of synapses per $25 \mathrm{\mu m}^{2}$. (H,J) Representative images of Golgi-Cox staining of dendritic spines in the hippocampus. Scale bar $=10 \mu \mathrm{m}$. (I,K) Statistical analysis of the average number of dendritic spines. (L,N) The protein levels of PSD-95 were detected in hippocampus using western blot and $(\mathrm{M}, \mathrm{O})$ quantified as ratio (in \%) of WT + EGFP/WT + Vehicle group. Values shown are expressed as mean $\pm \mathrm{SEM} ; \mathrm{n}=4-6 /$ group; ${ }^{*} \mathrm{P}<0.05,{ }^{* *} \mathrm{P}<0.01$, ${ }^{* * *} \mathrm{P}<0.001$ vs. 6-month-old APP/PS1 + EGFP or 6-month-old APP/PS1 + Vehicle group. CysLT 1 R, cysteinyl leukotriene receptor 1; LTP, long-term potentiation; fEPSPs, field excitatory postsynaptic potentials; WT, wild type; EGFP, enhanced green fluorescent protein; SEM, standard error of the mean.

important neurobiological foundation for learning and memory, and the modification of synaptic strength produced by LTP is widely thought to underlie memory storage $(34,35)$. Marked synapse loss was found in the brain, especially in hippocampus and cerebral cortex, of $\mathrm{AD}$ patients in previous findings. At 3 months of age, APP/PS1 mice also showed deficits in synaptic plasticity (36). We found impaired LTP, decreased dendritic spine density, synapse number, and PSD95 proteins in young APP/PS1 mice. More importantly, hippocampal $\mathrm{CysLT}_{1} \mathrm{R}$ overexpression and activation dramatically accelerate these changes in young APP/PS1 mice. Hippocampal-based LTP is one mechanism for the synaptic plasticity underlying explicit memory storage in mammals; therefore, following overexpression or activation of CysLT ${ }_{1} \mathrm{R}$, lower levels of fEPSP in the hippocampus represent not only impaired synaptic function, but also worsened cognitive function $(37,38)$.

Although the precise cause of $\mathrm{AD}$ remains elusive, it has been suggested that synaptic loss in $\mathrm{AD}$ is attributed to the accumulation of $A \beta(39)$, which is a cleavage product derived from amyloid precursor protein. On sequential cleavage by aspartyl proteases $\beta$ - and $\gamma$-secretase, APP generates various peptide species, including $A \beta_{1-40}, A \beta_{1-42}$, and so on, which are prone to oligomerization, leading to the formation of amyloid plaques (40). Our previous studies showed that
CysLT $_{1} \mathrm{R}$-mediated signaling referred to NF- $\kappa \mathrm{B}$ pathway, which led to elevations of APP and $\beta$ - and $\gamma$-secretases and subsequent increase of $A \beta$ production $(14,41)$. In APP/PS1 transgenic mice, CysLT $_{1} \mathrm{R}$ overexpression or activation did not influence APP, but increased expression of BACE1 and PS-1, subsequently led to A $\beta$ generation. This difference might be associated with animal status. The vast majority of potential disease-modifying treatments developed in recent years are directed against $\mathrm{A} \beta$, including inhibitors of the synthetic enzyme gamma-secretase and beta-secretase, and A $\beta$ aggregation inhibitors. However, the most elaborated anti-A $\beta$ approach is immunotherapy, including both active vaccines to stimulate the immune system to produce its own antibodies and passive immunization through the administration of exogenous antibodies. Although the development of therapies targeting $\mathrm{A} \beta$ for $\mathrm{AD}$ has been beset by disappointing results, these failures contain important clues as well as evidence of promise. These therapy trials, especially immunotherapy, may be started too late in disease-when too much $\mathrm{A} \beta$ has accumulated and the $\mathrm{A} \beta$ cascade is irrevocably initiated. We can expect new trials to be initiated ever earlier in the course of $\mathrm{AD}$.

Taken together, our study indicates that overexpression or activation of $\mathrm{CysLT}_{1} \mathrm{R}$ accelerates cognitive dysfunction in young APP/PS1 mice, which is involved in $\mathrm{A} \beta$ accumulation 
A

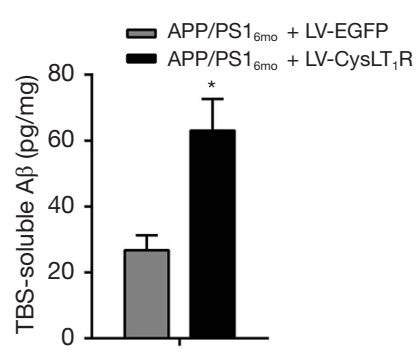

B

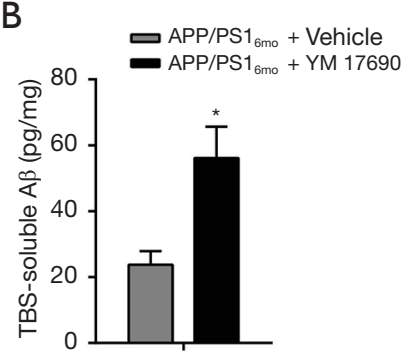

C

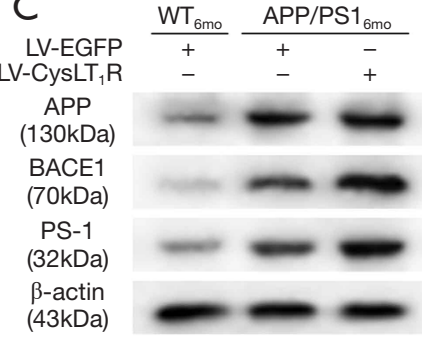

D
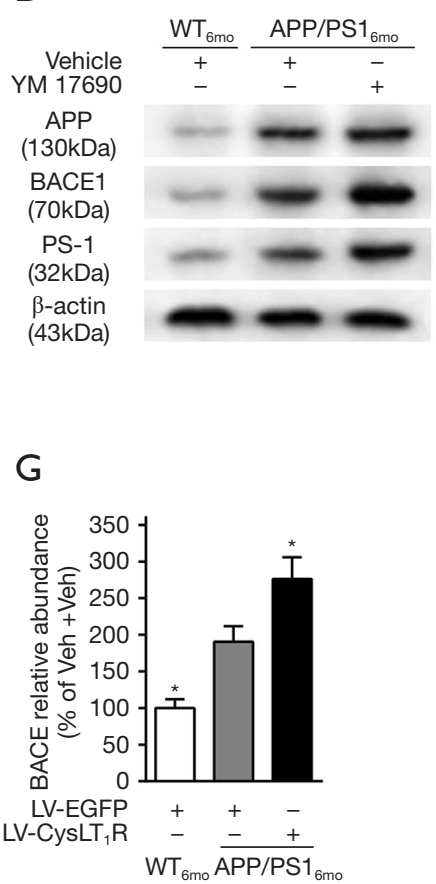

\section{E}

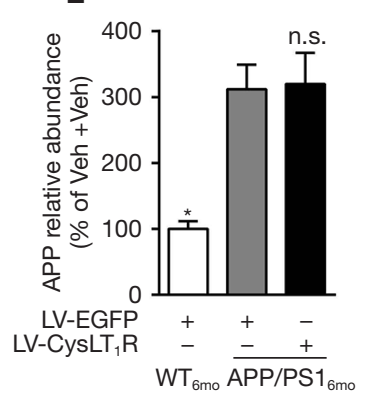

$\mathrm{H}$

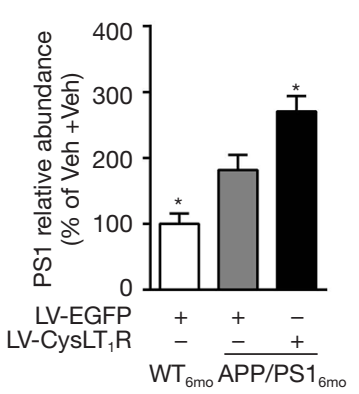

$\mathrm{F}$

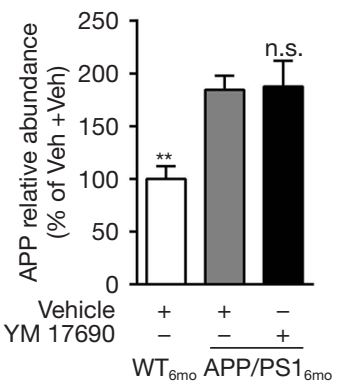

I

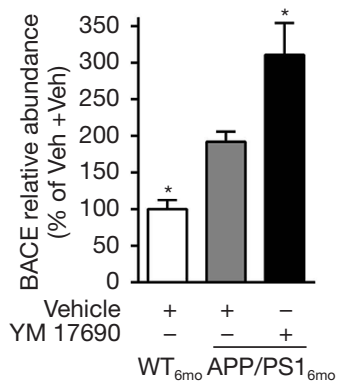

J

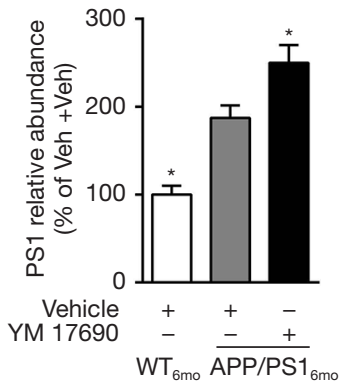

Figure 3 Hippocampal CysLT $\mathrm{R}_{1}$ Overexpression or activation exacerbates $\mathrm{A} \beta$ generation in young APP/PS1 transgenic mice. $(\mathrm{A}, \mathrm{B})$ The TBS-soluble forms of $A \beta_{1-40}$ in hippocampus were assessed by ELISA. (C,D) Representative western blot of APP, BACE, and PS1 in hippocampus. Quantification of (E,F) APP, (G,I) BACE, (H,J) PS1 levels were expressed as ration (in\%) of WT + EGFP/WT + Vehicle group. Values shown are expressed as mean $\pm \mathrm{SEM}$; $\mathrm{n}=4-6$ /group; ${ }^{*} \mathrm{P}<0.05$ vs. 6-month-old APP/PS1 + EGFP or 6-month-old APP/PS1 + Vehicle group. CysLT ${ }_{1} \mathrm{R}$, cysteinyl leukotriene receptor 1; TBS, Tris-buffered saline; A $\beta$, amyloid $\beta$; ELISA, enzyme-linked immunosorbent assay; APP, amyloid precursor protein; BACE, $\beta$-secretase; SEM, standard error of the mean.

and synaptic dysfunction. Our findings suggest that $\mathrm{Cys}_{\mathrm{LT}} \mathrm{R}$ could be a key player in the development of $\mathrm{AD}$ and could be targeted for the prevention and/or treatment of $\mathrm{AD}$.

\section{Acknowledgments}

We appreciate technical support provided by the Public Experimental Pharmacology Platform of China Pharmaceutical University.
Funding: This work was supported by grants from the National Natural Science Foundation of China (81573413 and 81773714 to Hao Hong) and the "Double First-Class" University Project (CPU2018GF/GY**).

\section{Footnote}

Reporting Checklist: The authors have completed the ARRIVE reporting checklist. Available at https://dx.doi. 


\section{Page 10 of 11}

org/10.21037/atm-21-4518

Data Sharing Statement: Available at https://dx.doi. org/10.21037/atm-21-4518

Conflicts of Interest: All authors have completed the ICMJE uniform disclosure form (available at https://dx.doi. org/10.21037/atm-21-4518). The authors have no conflicts of interest to declare.

Ethical Statement: The authors are accountable for all aspects of the work in ensuring that questions related to the accuracy or integrity of any part of the work are appropriately investigated and resolved. Experiments were performed under a project license granted by China Pharmaceutical University, in compliance with guidelines of China Pharmaceutical University for the care and use of animals.

Open Access Statement: This is an Open Access article distributed in accordance with the Creative Commons Attribution-NonCommercial-NoDerivs 4.0 International License (CC BY-NC-ND 4.0), which permits the noncommercial replication and distribution of the article with the strict proviso that no changes or edits are made and the original work is properly cited (including links to both the formal publication through the relevant DOI and the license). See: https://creativecommons.org/licenses/by-nc-nd/4.0/.

\section{References}

1. Koffie RM, Hyman BT, Spires-Jones TL. Alzheimer's disease: synapses gone cold. Mol Neurodegener 2011;6:63.

2. Bejanin A, Schonhaut DR, La Joie R, et al. Tau pathology and neurodegeneration contribute to cognitive impairment in Alzheimer's disease. Brain 2017;140:3286-300.

3. Uddin MS, Kabir MT, Rahman MS, et al. Revisiting the Amyloid Cascade Hypothesis: From Anti-A $\beta$ Therapeutics to Auspicious New Ways for Alzheimer's Disease. Int J Mol Sci 2020;21:5858.

4. Gouras GK, Olsson TT, Hansson O. $\beta$-Amyloid peptides and amyloid plaques in Alzheimer's disease. Neurotherapeutics 2015;12:3-11.

5. Seeburger JL, Holder DJ, Combrinck M, et al. Cerebrospinal fluid biomarkers distinguish postmortemconfirmed Alzheimer's disease from other dementias and healthy controls in the OPTIMA cohort. J Alzheimers Dis 2015;44:525-39.
Fang et al. CysLT1R accelerates memory deficits in APP/PS1 mice

6. Selkoe DJ, Hardy J. The amyloid hypothesis of Alzheimer's disease at 25 years. EMBO Mol Med 2016;8:595-608.

7. 2020 Alzheimer's disease facts and figures. Alzheimers Dement 2020. [Epub ahead of print].

8. Singh RK, Gupta S, Dastidar S, et al. Cysteinyl leukotrienes and their receptors: molecular and functional characteristics. Pharmacology 2010;85:336-49.

9. Drazen JM, Israel E, O'Byrne PM. Treatment of asthma with drugs modifying the leukotriene pathway. $\mathrm{N}$ Engl J Med 1999;340:197-206.

10. Zhang YJ, Zhang L, Ye YL, et al. Cysteinyl leukotriene receptors CysLT1 and CysLT2 are upregulated in acute neuronal injury after focal cerebral ischemia in mice. Acta Pharmacol Sin 2006;27:1553-60.

11. Ding Q, Fang SH, Zhou Y, et al. Cysteinyl leukotriene receptor 1 partially mediates brain cryoinjury in mice. Acta Pharmacol Sin 2007;28:945-52.

12. Zhang WP, Hu H, Zhang L, et al. Expression of cysteinyl leukotriene receptor 1 in human traumatic brain injury and brain tumors. Neurosci Lett 2004;363:247-51.

13. Wang L, Du C, Lv J, et al. Antiasthmatic drugs targeting the cysteinyl leukotriene receptor 1 alleviate central nervous system inflammatory cell infiltration and pathogenesis of experimental autoimmune encephalomyelitis. J Immunol 2011;187:2336-45.

14. Tang SS, Wang XY, Hong H, et al. Leukotriene D4 induces cognitive impairment through enhancement of CysLT 1 R-mediated amyloid- $\beta$ generation in mice. Neuropharmacology 2013;65:182-92.

15. Tang SS, Ji MJ, Chen L, et al. Protective effect of pranlukast on $\mathrm{A} \beta_{1-42}$-induced cognitive deficits associated with downregulation of cysteinyl leukotriene receptor 1 . Int J Neuropsychopharmacol 2014;17:581-92.

16. Tang SS, Hong H, Chen L, et al. Involvement of cysteinyl leukotriene receptor 1 in A $\beta 1-42$-induced neurotoxicity in vitro and in vivo. Neurobiol Aging 2014;35:590-9.

17. Lai J, Hu M, Wang H, et al. Montelukast targeting the cysteinyl leukotriene receptor 1 ameliorates A $\beta 1-42$ induced memory impairment and neuroinflammatory and apoptotic responses in mice. Neuropharmacology 2014;79:707-14.

18. Ghosh A, Chen F, Wu F, et al. CysLT1R downregulation reverses intracerebroventricular streptozotocin-induced memory impairment via modulation of neuroinflammation in mice. Prog Neuropsychopharmacol Biol Psychiatry 2017;73:19-30.

19. Chen F, Ghosh A, Wu F, et al. Preventive effect of genetic 
knockdown and pharmacological blockade of CysLT1R on lipopolysaccharide (LPS)-induced memory deficit and neurotoxicity in vivo. Brain Behav Immun 2017;60:255-69.

20. Chen F, Fang S, Du Y, et al. CRISPR/Cas9-mediated CysLT1R deletion reverses synaptic failure, amyloidosis and cognitive impairment in APP/PS1 mice. Aging (Albany NY) 2021;13:6634-61.

21. Kilkenny C, Browne W, Cuthill IC, et al. Animal research: reporting in vivo experiments: the ARRIVE guidelines. J Gene Med 2010;12:561-3.

22. McGrath JC, Lilley E. Implementing guidelines on reporting research using animals (ARRIVE etc.): new requirements for publication in BJP. Br J Pharmacol 2015;172:3189-93.

23. Fang SC, Xie H, Chen F, et al. Simvastatin ameliorates memory impairment and neurotoxicity in streptozotocininduced diabetic mice. Neuroscience 2017;355:200-11.

24. Wang H, Tan YZ, Mu RH, et al. Takeda G ProteinCoupled Receptor 5 Modulates Depression-like Behaviors via Hippocampal CA3 Pyramidal Neurons Afferent to Dorsolateral Septum. Biol Psychiatry 2021;89:1084-95.

25. Wu X, Lv YG, Du YF, et al. Neuroprotective effects of INT-777 against A $\beta 1$-42-induced cognitive impairment, neuroinflammation, apoptosis, and synaptic dysfunction in mice. Brain Behav Immun 2018;73:533-45.

26. Zhao D, Meng J, Zhao Y, et al. RPS23RG1 Is Required for Synaptic Integrity and Rescues Alzheimer's Disease-Associated Cognitive Deficits. Biol Psychiatry 2019;86:171-84.

27. Wu X, Lv YG, Du YF, et al. Inhibitory effect of INT777 on lipopolysaccharide-induced cognitive impairment, neuroinflammation, apoptosis, and synaptic dysfunction in mice. Prog Neuropsychopharmacol Biol Psychiatry 2019;88:360-74.

28. Chiang ACA, Huo X, Kavelaars A, et al. Chemotherapy accelerates age-related development of tauopathy and results in loss of synaptic integrity and cognitive impairment. Brain Behav Immun 2019;79:319-25.

29. Ung DC, Iacono G, Méziane H, et al. Ptchd1 deficiency induces excitatory synaptic and cognitive dysfunctions in mouse. Mol Psychiatry 2018;23:1356-67.

30. Matthews $\mathrm{KA}, \mathrm{Xu}$ W, Gaglioti $\mathrm{AH}$, et al. Racial and ethnic estimates of Alzheimer's disease and related dementias in the United States (2015-2060) in adults aged $\geq 65$ years. Alzheimers Dement 2019;15:17-24.

31. Bilkei-Gorzo A. Genetic mouse models of brain ageing and Alzheimer's disease. Pharmacol Ther 2014;142:244-57.

32. Jin L, Pan Y, Tran NLL, et al. Intestinal Permeability and Oral Absorption of Selected Drugs Are Reduced in a Mouse Model of Familial Alzheimer's Disease. Mol Pharm 2020;17:1527-37.

33. Kelly P, Denver P, Satchell SC, et al. Microvascular ultrastructural changes precede cognitive impairment in the murine APPswe/PS1dE9 model of Alzheimer's disease. Angiogenesis 2017;20:567-80.

34. Lisman J, Cooper K, Sehgal M, et al. Memory formation depends on both synapse-specific modifications of synaptic strength and cell-specific increases in excitability. Nat Neurosci 2018;21:309-14.

35. Neves G, Cooke SF, Bliss TV. Synaptic plasticity, memory and the hippocampus: a neural network approach to causality. Nat Rev Neurosci 2008;9:65-75.

36. Volianskis A, Køstner R, Mølgaard M, et al. Episodic memory deficits are not related to altered glutamatergic synaptic transmission and plasticity in the CA1 hippocampus of the APPswe/PS18E9-deleted transgenic mice model of $§$-amyloidosis. Neurobiol Aging 2010;31:1173-87.

37. Pereda D, Al-Osta I, Okorocha AE, et al. Changes in presynaptic calcium signalling accompany age-related deficits in hippocampal LTP and cognitive impairment. Aging Cell 2019;18:e13008.

38. Sri S, Pegasiou CM, Cave CA, et al. Emergence of synaptic and cognitive impairment in a mature-onset APP mouse model of Alzheimer's disease. Acta Neuropathol Commun 2019;7:25.

39. Kashyap G, Bapat D, Das D, et al. Synapse loss and progress of Alzheimer's disease -A network model. Sci Rep 2019;9:6555.

40. De Strooper B, Annaert W. Proteolytic processing and cell biological functions of the amyloid precursor protein. J Cell Sci 2000;113:1857-70.

41. Wang XY, Tang SS, Hu M, et al. Leukotriene D4 induces amyloid- $\beta$ generation via CysLT(1)R-mediated $\mathrm{NF}-\kappa \mathrm{B}$ pathways in primary neurons. Neurochem Int 2013;62:340-7.

(English Language Editor: J. Jones)

Cite this article as: Fang SC, Wang JJ, Chen F, Tang SS, Mu RH, Yuan DH, Zhao JJ, Hong H, Long Y. Hippocampal CysLT1R overexpression or activation accelerates memory deficits, synaptic dysfunction, and amyloidogenesis in young APP/PS1 transgenic mice. Ann Transl Med 2021;9(20):1531. doi: $10.21037 /$ atm-21-4518 